\title{
DISCONTINUOUS FUNCTIONS IN GALE ECONOMIC MODEL
}

\section{BULA}

University of Latvia

Raiņa bulv. 19, Rīga LV 1586, Latvia

E-mail: buls@lanet.Iv

Received December 3, 2002; revised March 19, 2003

\begin{abstract}
The concept of a general economic equilibrium based on balance of supply and demand has played a central role in theoretical economics since very beginning. One of the basic assumptions in mathematical modelling of the equilibrium economic model is the continuity of functions describing the model. This article analyses simplified version of Gale model from year 1955 by weakening the condition of strict convexity and continuity of utilities functions and proving existence of quasi-equilibrium in generalized Gale model. MSC 2000: 91B24, 91B42, 91B50, 26A15
\end{abstract}

Key words: economic equilibrium, mathematichal modelling, equilibrium economic model, quasi-equilibrium, Gale model

\section{INTRODUCTION}

One of the basic assumptions in mathematical modelling of the equilibrium economic model is the continuity of the supply function, excess demand function, utility function or multi-function (see, for example, $[1 ; 2 ; 3 ; 4 ; 7 ; 8 ; 9$; 10]) involved. There are reasons to maintain the necessity of this assumption of continuity because the appropriate mathematical tools are available (fixed point theorems of Bohl-Brouwer-Schauder and Kakutani), that substantiate, the existence of equilibrium. The article [6] offers to change the continuity of the excess-demand functions to the $w$-continuity of these functions, examines the properties of $w$-discontinuous mappings and finally proves the existence of quasi-equilibrium. The proof of results of [6] are based on the idea that $w$-discontinuous function can be approximated with a continuous function (see [5]). In fact, if we assume that functions are continuous, but in reality they are discontinuous, our results lack precision. 
In this article we analyse a simplified version [4] of economic Gale model [9]. We weaken the condition of strict convexity and continuity of utilities functions. We make the assumption that utilities functions can be approximated with strict convex and continuous functions. If this assumption is fulfilled our utilities functions are bounded and this is important property with applicability in economics.

In this article we prove the existence of quasi-equilibria in generalized Gale model. One question still remains open - what are the functions that can be approximated very well with strict convex and continuous functions.

\section{THE GALE MODEL}

At first we shortly describe the simplified version [4] of Gale model [9].

The model to be considered involves $n$ goods $G_{1}, G_{2}, \ldots, G_{n}$ and $m$ economic agents $A_{1}, A_{2}, \ldots, A_{m}$. The set of goods includes all types of labour and services as well as material commodities. The economic agents may be thought of as either consumers or as producers.

The amounts of the goods $G_{1}, G_{2}, \ldots, G_{n}$ supplied or consumed by an agent $A_{i}$ in a certain fixed time interval may be given by a vector $x_{i}=$ $\left(x_{i 1}, x_{i 2}, \ldots, x_{i n}\right)$ in $\boldsymbol{R}^{n}$. The $j^{\text {th }}$ coordinate $x_{i j}$ represents the amount of the item $G_{j}$ and is positive or negative depending on whether $G_{j}$ is supplied or consumed, respectively. Such vector is called a commodity bundle of $A_{i}$. In general, an agent is able to act in various ways. The set $X_{i}$ of all possible commodity bundles $x_{i}$ is called the commodity set or technology set of the agent $A_{i}, i=1,2, \ldots, m$.

Also balance inequalities hold, i.e., the total amount of each item consumed by all agents must not exceed the total amount supplied

$$
\sum_{i=1}^{m} x_{i} \geq 0 \text { or } \sum_{i=1}^{m} x_{i j} \geq 0, j=1,2, \ldots, n .
$$

Definition 2.1. The vector system $\left\{x_{1}, x_{2}, \ldots, x_{m}\right\}$ is called feasible allocation of economy if $x_{i} \in X_{i}, i=1,2, \ldots, m$, and $\sum_{i=1}^{m} x_{i} \geq 0$.

Suppose utility function exists for every agent $A_{i}$

$$
f_{i}: X_{i} \rightarrow \boldsymbol{R}, \quad i=1,2, \ldots, m .
$$

Definition 2.2. The feasible allocation $\left\{\overline{x_{1}}, \overline{x_{2}}, \ldots, \overline{x_{m}}\right\}$ is Pareto optimal allocation if for every another feasible allocation $\left\{x_{1}, x_{2}, \ldots, x_{m}\right\}$ that follows

a) $\forall i \in\{1,2, \ldots, m\}: \quad f_{i}\left(x_{i}\right)=f_{i}\left(\overline{x_{i}}\right)$, or

b) $\exists A_{i}: \quad f_{i}\left(x_{i}\right)<f_{i}\left(\overline{x_{i}}\right)$. 
We assume, that in this economic system administrative personnel exists who has the goal to ensure Pareto optimal allocation. Administrative personnel offers price vector $p=\left(p_{1}, p_{2}, \ldots, p_{m}\right)$, purchases goods from economic agents, that are willing to sell the goods for offered prices, and economic agents buy the goods from administrative personnel for the offered prices.

Mathematically: $\forall A_{i}, i=1,2, \ldots, m$, allocation $x_{i}$ is solution of system

$$
\left\{\begin{array}{l}
f_{i}\left(x_{i}\right) \rightarrow \max \\
\left(p, x_{i}\right) \geq 0, x_{i} \in X_{i}
\end{array}\right.
$$

We denote the solution of this system as $x_{i}(p)$. If prices are freely given, allocations $x_{i}(p)$ may not satisfy the balance inequality $\sum_{i=1}^{m} x_{i}(p) \geq 0$.

Definition 2.3. A price vector $p^{*}$ and feasible allocation $\left\{x_{1}^{*}, x_{2}^{*}, \ldots, x_{n}^{*}\right\}$ are called an equilibrium if $\sum_{i=1}^{m} x_{i}\left(p^{*}\right) \geq 0$ and $x_{i}\left(p^{*}\right)$ is a solution for (2.1); the allocation $\left\{x_{1}^{*}, x_{2}^{*}, \ldots, x_{m}^{*}\right\}$ is called an equilibrium allocation and $p^{*}$ is called an equilibrium price system.

In this situation we make following assumptions.

A1. The technology sets $X_{i} \subset \boldsymbol{R}^{n}, i=1,2, \ldots, m$, are convex, closed, bounded.

A2. $\forall p \in S_{n} \quad \forall X_{i}, i=1,2, \ldots, m, \quad \exists \overline{x_{i}}:\left(p, \overline{x_{i}}\right)>0$, where $S_{n}=\left\{p=\left(p_{1}, p_{2}, \ldots, p_{n}\right) \mid \sum_{i=1}^{n} p_{i}=1, p_{i} \geq 0, i=1,2, \ldots, m\right\}$.

A3. The utility functions $f_{i}, i=1,2, \ldots, m$, are strictly convex and continuous.

Now it is possible to prove the following result that is essential to Gale model.

Theorem 2.1. (Gale [9]) If economy with finite number of goods and agents satisfies the assumptions $\mathrm{A} 1-\mathrm{A} 3$, there exists an equilibrium.

\section{GENERALIZED GALE MODEL}

Our purpose in this article is to weaken the condition of strict convexity and continuity of utilities functions in Assumption 3.

Why was Assumption 3 made? The convexity of utilities functions is based on hypothesis that the change of the value of utilities function from commodity bundle $x$ to commodity bundle $x+\Delta x$ is greater than the value change going from commodity bundle $x+\Delta x$ to commodity bundle $x+2 \Delta x$ irrespective of $x$ and $\Delta x$. This hypothesis means that the utility function $f$ satisfies the inequality

$$
f(x+\Delta x)-f(x) \geq f(x+2 \Delta x)-f(x+\Delta x) .
$$


From this inequality it is possible to conclude that $f$ is a convex function (for example in [4] we find the proof for twice differentiable functions).

The condition of strict convexity of utilities functions in Gale model has appeared because the strict convex functions in convex set (technology sets by Assumption 1 are convex) have no more than one point of maximum. Since the technology sets are closed and bounded (i.e., compact sets in $\boldsymbol{R}^{n}$ ) the condition of continuity makes it possible for the utilities functions to reach the maximum.

From this analysis we conclude that conditions of continuity and strict convexity of utilities functions in Gale model are more necessary for mathematical reasons than economic reasons. However, if a function is convex in convex set, then it is continuous in every inner point of the set (see [11]). The function often achieves the maximum value in boundary points. This requires the condition of continuity of utilities functions in all technology sets in Gale model and this condition is independent from the condition of strict convexity.

The non-convexity of utilities functions is based on the fact that hypothesis of value changes of utilities functions in all situations is not true, for example, when the demand of goods is satiated or if the consumer is impacted by marketing or other consumers behaviour.

Assumption 3'.

$\exists \mu>0 \quad \exists \bar{f}_{i}: X_{i} \rightarrow \boldsymbol{R}-$ strictly convex and continuous functions such that

$$
\left|\bar{f}_{i}\left(x_{i}\right)-f_{i}\left(x_{i}\right)\right| \leq \mu, \quad \forall x_{i} \in X_{i}, \quad i=1,2, \ldots, m .
$$

We replace Assumption 3 in Gale model with Assumption 3' and call this new model as generalized Gale model.

Proposition 3.1. If Assumption 3' is satisfied, utility functions are bounded.

Proof. Since the technology sets $X_{i}$ are compact sets and $\bar{f}_{i}$ are continuous functions then $\bar{f}_{i}\left(X_{i}\right)$ are compact sets and also bounded sets

$$
\exists r>0 \forall x_{i} \in X_{i}:\left|\bar{f}_{i}\left(x_{i}\right)\right|<r \text { or }-r<\bar{f}_{i}\left(x_{i}\right)<r, i=1,2, \ldots, m .
$$

Since $\bar{f}_{i}$ are approximations of utility functions, i.e.,

$$
\forall x_{i} \in X_{i}:\left|f_{i}\left(x_{i}\right)-\bar{f}_{i}\left(x_{i}\right)\right| \leq \mu
$$

or

$$
\bar{f}_{i}\left(x_{i}\right)-\mu \leq f_{i}\left(x_{i}\right) \leq \bar{f}_{i}\left(x_{i}\right)+\mu,
$$

then from (3.1) it follows that

$$
\left|f_{i}\left(x_{i}\right)\right|<r+\mu, \forall x_{i} \in X_{i}, i=1,2, \ldots, m,
$$


i.e., utilities functions are bounded.

The utilities functions may not reach the maximum value in generalized Gale model. From Proposition 3.1 it follows that we should investigate such allocations that give value that is close to supremum value. These allocations and price vectors are called quasi-equilibrium. They are defined in the following way.

Definition 3.1. A price vector $p^{*}$ and feasible allocation $\left\{x_{1}^{*}, x_{2}^{*}, \ldots, x_{n}^{*}\right\}$ are called a quasi-equilibrium if $\sum_{i=1}^{m} x_{i}\left(p^{*}\right) \geq 0$ and $x_{i}\left(p^{*}\right)$ is "near solution" for

$$
\left\{\begin{array}{l}
f_{i}\left(x_{i}\right) \rightarrow \sup \\
\left(p^{*}, x_{i}\right) \geq 0, x_{i} \in X_{i}
\end{array},\right. \text { i.e. }
$$

$\exists \gamma \geq 0\left|\sup _{\substack{x_{i} \in X_{i} \\\left(p^{*}, x_{i}\right) \geq 0}} f_{i}\left(x_{i}\right)-f_{i}\left(x_{i}\left(p^{*}\right)\right)\right| \leq \gamma, \quad i=1,2, \ldots, m$.

If $\gamma=0$ then we have the equilibrium in the classical sense; if $\gamma>0$ then we would like to have $\gamma$ as small as possible.

We use the following lemma in the proof of existence of quasi-equilibrium in generalized Gale model.

Lemma 3.1. Let $f, \bar{f}: A \rightarrow \boldsymbol{R} \quad\left(A \subset \boldsymbol{R}^{n}\right)$,

$$
\exists \mu>0 \quad \forall x \in A:|f(x)-\bar{f}(x)| \leq \mu,
$$

$\exists \max \bar{f}(x) \in \boldsymbol{R}$ and $\exists \sup f(x) \in \boldsymbol{R}$. Then

$$
\left|\max _{x \in A} \bar{f}(x)-\sup _{x \in A} f(x)\right| \leq \mu .
$$

Proof. Suppose

$$
\left|\max _{x \in A} \bar{f}(x)-\sup _{x \in A} f(x)\right|>\mu .
$$

Then two cases are possible.

Case I. $\max _{x \in A} \bar{f}(x)-\sup _{x \in A} f(x)>\mu \geq 0$.

Then $\max _{x \in A} \bar{f}(x)=\bar{f}\left(x^{*}\right)>\mu+\sup f(x) \geq \mu+f(x), \forall x \in A$. Since $x^{*} \in A$ therefore in special case it follows that

$$
\bar{f}\left(x^{*}\right)>\mu+f\left(x^{*}\right) \text { or } \bar{f}\left(x^{*}\right)-f\left(x^{*}\right)>\mu-
$$


which is in contradiction with (3.2).

Case II. $\max _{x \in A} \bar{f}(x)-\sup _{x \in A} f(x)<-\mu \geq 0$ or $\sup _{x \in A} f(x)-\max _{x \in A} \bar{f}(x)>\mu \geq 0$. We denote

$$
\sup _{x \in A} f(x)-\max _{x \in A} \bar{f}(x)-\mu=\alpha>0
$$

and choose $\varepsilon=\frac{\alpha}{2}$. From the definition of supremum it follows that

$$
\forall \varepsilon>0 \exists f(x): \sup _{x \in A} f(x)<f(x)+\varepsilon .
$$

If $\varepsilon=\frac{\alpha}{2}$ then $\exists f\left(x_{1}\right)\left(x_{1} \in A\right)$ such that $\sup _{x \in A} f(x)<f\left(x_{1}\right)+\varepsilon$.

Since $\forall x \in A: \max _{x \in A} \bar{f}(x) \geq \bar{f}(x)$ then we can arrive to contradiction in the following way

$$
\begin{aligned}
\alpha & =\sup _{x \in A} f(x)-\max _{x \in A} \bar{f}(x)-\mu<f\left(x_{1}\right)+\varepsilon-\max _{x \in A} \bar{f}(x)-\mu \\
& =f\left(x_{1}\right)-\bar{f}\left(x_{1}\right)+\bar{f}\left(x_{1}\right)+\varepsilon-\max _{x \in A} \bar{f}(x)-\mu \\
& \leq \mu+\bar{f}\left(x_{1}\right)+\varepsilon-\max _{x \in A} \bar{f}(x)-\mu \leq \max _{x \in A} \bar{f}(x)+\varepsilon-\max _{x \in A} \bar{f}(x) \\
& =\varepsilon=\frac{\alpha}{2} \Rightarrow 0<\alpha \leq \frac{\alpha}{2} .
\end{aligned}
$$

Now we prove the main result of quasi-equilibrium.

Theorem 3.1. If economy with finite number of goods and agents satisfies the assumptions A1, A2, A3', then there exists a quasi-equilibrium and $\gamma \leq 2 \mu$.

Proof. We denote as $\bar{f}_{i}$ the approximative function of utilities function $f_{i}$, $i=1,2, \ldots, m$. This function is strictly convex and continuous by A3'. Since the remaining assumptions of generalized Gale model are the same as in Gale model then we have the situation as in classical Gale model of Section 2. We can assert by Theorem 2.1 that in this situation an equilibrium (in sense of Definition 2.3) exists, i.e., there exists such a price vector $\hat{p}$ that $\sum_{i=1}^{m} x_{i}(\hat{p}) \geq 0$ where $x_{i}(\hat{p})$ is the solution of system

$$
\left\{\begin{array}{l}
\bar{f}_{i}\left(x_{i}\right) \rightarrow \max \\
\left(\hat{p}, x_{i}\right) \geq 0, x_{i} \in X_{i}
\end{array}, \quad i=1,2, \ldots, m\right.
$$

Now we prove that this price $\hat{p}$ and the solution $x_{i}(\hat{p})$ are quasi-equilibrium of generalized Gale model. By Definition 3.1 we need to prove that $x_{i}(\hat{p})$ is 
also close to the solution of system

$$
\left\{\begin{array}{l}
f_{i}\left(x_{i}\right) \rightarrow \sup \\
\left(\hat{p}, x_{i}\right) \geq 0, x_{i} \in X_{i}
\end{array}, \quad i=1,2, \ldots, m\right.
$$

We prove that $\gamma \leq 2 \mu$ where $\mu$ is a constant of approximation of utilities functions $f_{i}$ with strictly convex and continuous functions $\bar{f}_{i}$.

In the situation described in Theorem 3.1, because of Lemma 3.1, it is true that

$$
\left|\max _{\substack{x_{i} \in X_{i},\left(\hat{p}, x_{i}\right) \geq 0}} \bar{f}_{i}\left(x_{i}\right)-\sup _{\substack{x_{i} \in X_{i},\left(\hat{p}, x_{i}\right) \geq 0}} f_{i}\left(x_{i}\right)\right| \leq \mu, i=1,2, \ldots, m
$$

Therefore we get the following equalities and inequalities that conclude the proof:

$$
\begin{aligned}
& \sup _{\substack{x_{i} \in X_{i},\left(\hat{p}, x_{i}\right) \geq 0}} f_{i}\left(x_{i}\right)-f_{i}\left(x_{i}(\hat{p})\right) \mid \\
& =\mid \sup _{x_{i} \in X_{i},} f_{i}\left(x_{i}\right)-\bar{f}_{i}\left(x_{i}(\hat{p})\right)+\bar{f}_{i}\left(x_{i}(\hat{p})-f_{i}\left(x_{i}(\hat{p})\right) \mid\right. \\
& \left(\hat{p}, x_{i}\right) \geq 0 \\
& \leq\left|\sup _{x_{i} \in X_{i},} f_{i}\left(x_{i}\right)-\bar{f}_{i}\left(x_{i}(\hat{p})\right)\right|+\mid \bar{f}_{i}\left(x_{i}(\hat{p})-f_{i}\left(x_{i}(\hat{p})\right) \mid\right. \\
& \left(\hat{p}, x_{i}\right) \geq 0 \\
& =\left|\sup _{\substack{x_{i} \in X_{i},\left(\hat{p}, x_{i}\right) \geq 0}} f_{i}\left(x_{i}\right)-\max _{\substack{x_{i} \in X_{i},\left(\hat{p}, x_{i}\right) \geq 0}} \bar{f}_{i}\left(x_{i}\right)\right|+\mid \bar{f}_{i}\left(x_{i}(\hat{p})-f_{i}\left(x_{i}(\hat{p})\right) \mid\right. \\
& \leq \mu+\mu=2 \mu \text {. }
\end{aligned}
$$

\section{EXAMPLES AND CONCLUSIONS}

\section{Example 4.1.}

We shall start with the case with a single item and a single agent. Let the price $p>0$. Let $x$ be the amount of this item and $0 \leq x \leq 4$. We shall assume that there exists the utility function $f:[0,4] \rightarrow \boldsymbol{R}$

$$
f(x)= \begin{cases}0, & 0 \leq x<1 \\ 1, & 1 \leq x<2 \\ 2, & 2 \leq x<2.5 \\ 1, & 2.5 \leq x \leq 4\end{cases}
$$


for the agent (see Fig.1). The reason why the step-function can be utility function follows from the following idea: if the number of items is not integer (for example, car or shoes) then the usefulness of $1 \frac{1}{2}$ or $1 \frac{3}{4}$ of it is the same as of one item.

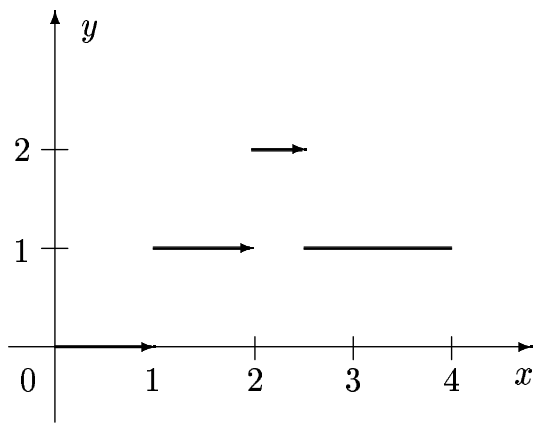

Fig. 1. The graph of $f(x)$.

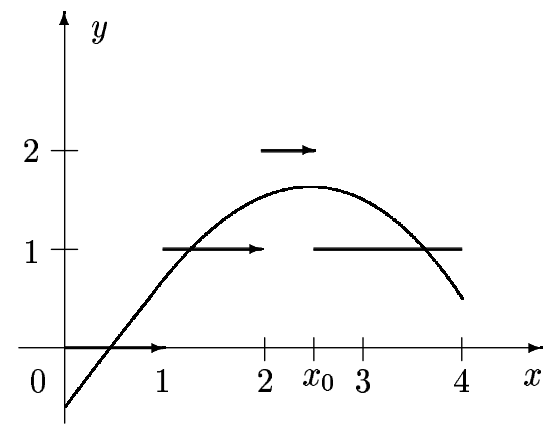

Fig. 2. The graphs of $f(x)$ and $\bar{f}(x)$.

We select strictly convex and continuous function $\bar{f}$ for approximation. Parabola $y=a x^{2}+b x+c, a<0$, is the function in the class of real-valued functions that possesses the strict convexity and continuity.

Finding strictly convex and continuous function being the closest to the given utility function $f$ is a statistical problem in general case.

We shall assume that parabola

$$
\bar{f}(x)=\alpha x^{2}+\beta x+\delta, 0 \leq x \leq 4, a<0,
$$

in Fig.2 is an approximation function. It is obvious that constant of approximation is $\mu \geq 0.5$ because the function $f$ has points of discontinuity with one unit jumps. In Fig. $20.5<\mu<1$. The approximation function $\bar{f}$ has maximum value in point $x_{0}=2.5$. Since $p>0$ and $\left(p, x_{0}\right) \geq 0$ then the pair $\left(p, x_{0}\right)$ is an equilibrium in classical Gale model. The pair $\left(p, x_{0}\right)$ is a solution also for generalized Gale model, i.e. the pair $\left(p, x_{0}\right)$ is quasi-equilibrium with

$$
\gamma=\left|\sup _{x \in[0,4]} f(x)-f\left(x_{0}\right)\right|=1 \leq 2 \mu .
$$

However this example is not interesting because we considered only a single item. The model with at least two goods would be more interesting.

Example 4.2. We consider the case with two goods and one agent. Let the price vector $\left(p_{1}, p_{2}\right) \geq 0$. Let $x$ and $y$ be the amounts of the first and the second items respectively, and $0 \leq x \leq 4,0 \leq y \leq 4$. Suppose that the utility 
function $f:[0,4] \times[0,4] \rightarrow \boldsymbol{R}$

$$
f(x, y)= \begin{cases}0, & 0 \leq x^{2}+y^{2}<1 \\ 1, & 1 \leq x^{2}+y^{2}<2^{2} \\ 2, & 2^{2} \leq x^{2}+y^{2}<(2.5)^{2} \\ 1, & (2.5)^{2} \leq x^{2}+y^{2} \leq 4^{2}\end{cases}
$$

exists for the agent. The projection of graph of $f$ in $z x$-plane is equivalent with graph of $f$ from Example 4.1. Therefore we approximate this $f$ with paraboloid

$$
\bar{f}(x, y)=\alpha\left(x^{2}+y^{2}\right)+\beta(x+y)+\delta, 0 \leq x \leq 4,0 \leq y \leq 4, \alpha<0
$$

(constants $\alpha, \beta, \delta$ are as in Example 4.1 for $\bar{f}$ ). Indeed this paraboloid is continuous and strictly convex function because if the function is twice differentiable then it is strictly convex if and only if the matrix of the second derivatives in every point of domain of function is negatively definite quadratic form ([4]). In our example the matrix is $\left(\begin{array}{cc}2 \alpha & 0 \\ 0 & 2 \alpha\end{array}\right)$ and, if $\alpha<0$, then it is negatively definite.

Similar to Example 4.1 we see that $\left(p_{1}, p_{2}\right)$ and $\left(x_{0}, y_{0}\right)=(2.5,2.5)$ is quasiequilibrium with constant

$$
\gamma=\left|\sup _{x, y \in[0,4] \times[0,4]} f(x, y)-\bar{f}(2.5,2.5)\right|=1 \leq 2 \mu .
$$

From these two examples and Theorem 3.1 we make the following three conclusions:

1. There exist such discontinuous functions that can be approximated with strictly convex and continuous functions. It is an open mathematical problem to find the kind of conditions these functions need to satisfy. From view of economics we can ask a question is it possible to approximate the discontinuous function with strictly convex and continuous function? Could this discontinuous function be the utility function?

2 . The constant $2 \mu$ in Theorem 3.1 shows how big the maximal error is possible if the real utility functions $f_{i}$ are approximated with strictly convex and continuous functions $\bar{f}_{i}$ and the solution of system

$$
\left\{\begin{array}{l}
\bar{f}_{i}\left(x_{i}\right) \rightarrow \max \\
\left(p^{*}, x_{i}\right) \geq 0, x_{i} \in X_{i}
\end{array}\right.
$$

is used as "near solution" for system

$$
\left\{\begin{array}{l}
f_{i}\left(x_{i}\right) \rightarrow \sup \\
\left(p^{*}, x_{i}\right) \geq 0, x_{i} \in X_{i}
\end{array}\right.
$$


From Examples 4.1 and 4.2 it follows that "approximate solution" can indeed be the solution of the real system, but also it is possible that difference

$$
\left|\sup _{\substack{x_{i} \in X_{i} \\\left(p^{*}, x_{i}\right) \geq 0}} f_{i}\left(x_{i}\right)-f_{i}\left(x_{i}\left(p^{*}\right)\right)\right|, \quad i=1,2, \ldots, m,
$$

reaches its maximum.

3. The general conclusion - if we approximate discontinuous functions with desirable functions that satisfy the necessary properties of mathematical tools (like strict convexity and continuity) then solution of approximated problem can be either the best solution possible or it can be the solution far from being the best solution. Without knowing the real functions we cannot estimate the amount of errors we make.

\section{REFERENCES}

[1] C.D. Aliprantis, D.J. Brown and O. Burkinshaw. Existence and optimality of competitive equilibria. Springer-Verlag, Berlin, Heidelberg, New York et., 1990.

[2] K.J. Arrow and G. Debreu. Existence of equilibrium for a competitive economy. Econometrica, 42, 265-290, 1954.

[3] K.J. Arrow and F.H. Hahn. General competitive analysis. North-Holland Publ.Company, 1991.

[4] E.M. Braverman. Matematiceskie modeli planirovanija $i$ upravlenija v ekonomiceskix sistemax. Nauka, Moscow, 1976. (in Russian)

[5] I. Bula. On the stability of Bohl-Brouwer-Schauder theorem. 26, 1859-1868, 1996.

[6] I. Bula and M.R. Weber. On discontinuous functions and their application to equilibria in some economic model. Preprint of Technische Universität Dresden, MATH-AN-0202, 2002.

[7] R.R. Cornwall. Introduction to the use of general equilibrium analysis. North-Holland Publ. Company, 1984.

[8] G. Debreu. Theory of Value. New York, 1959.

[9] D. Gale. The law of supply and demand. Mathematica Scandinavica, 3, 155, 1955.

[10] W. Hildenbrand and A.P. Kirman. Equilibrium Analysis. North-Holland Publ. Company, 1991.

[11] H. Nikaido. Convex structures and economic theory. Academic Press, New York and London, 1968.

\section{Trūkios funkcijos Geilo ekonominiame modelyje}

\section{Bula}

Ekonominès pusiausyros tarp atsargu ir poreikio sąvoka vaidina svrbų vaidmeni ekonometrikos teorijoje ir yra pradinèje vystymosi stadijoje. Matematiniame modeliavime viena iš pagrindinių prielaidų yra funkcijų, aprašančiu ekonominès pusiausvyros sąlygas, todydumas. Šis straipsnis nagrinėja supaprastintą Geilo modelio (pateiktą $1955 \mathrm{~m}$.) versiją, susilpninant pelno funkcijų tolydumo ir griežto iškilumo sąlygas. İrodoma, kad apibendrintame Geilo modelyje kvazipusiausvyros sąlyga egzistuoja. 